\title{
Ginkgo biloba extract enhances chemotherapy sensitivity and reverses chemoresistance through suppression of the KSR1-mediated ERK1/2 pathway in gastric cancer cells
}

\author{
SHI-QUAN LIU* , CHUN-YAN XU* , MENG-BIN QIN, LIN TAN, CHUN-FENG ZHUGE, \\ YE-BO MAO, MING-YU LAI and JIE-AN HUANG \\ Department of Gastroenterology, The First Affiliated Hospital of Guangxi Medical University, \\ Nanning, Guangxi 530021, P.R. China
}

Received January 9, 2015; Accepted April 6, 2015

DOI: 10.3892/or.2015.3923

\begin{abstract}
Kinase suppressor of Ras 1 (KSR1) is a scaffold protein that modulates the activation of the oncogenic mitogen-activated protein kinase (MAPK)/extracellular signal-regulated kinase (ERK) signaling pathway. Ginkgo biloba extract (EGb) 761 has been demonstrated to possess antitumor activity that may be related to the KSR1-mediated ERK signaling pathway. However, the roles and its underlying mechanism in gastric cancer are unclear. In the present study, 62 gastric cancer and matched normal tissues were exploited for immunohistochemistry and real-time fluorescent quantitative PCR detection. Results of the immunohistochemistry showed that the expression of ERK $1 / 2$ and p-ERK1/2 was correlated to the expression of KSR1 and p-KSR1 in the gastric cancer tissues, and the overexpression of KSR1, p-KSR1, ERK1/2 and p-ERK1/2 was significantly associated with histological grade, TNM stage, lymph node and distant metastasis. Compared with the normal tissues, the relative mRNA copy values of KSR1, ERK1 and ERK2 in the cancer tissues were $2.43 \pm 0.49,2.10 \pm 0.44$ and $3.65 \pm 0.94$. In addition, the expression of KSR1, p-KSR1, ERK1/2 and p-ERK1/2 in human gastric cancer multidrug resistant SGC-7901/CDDP cells was higher than that in the SGC-7901 cells as detected by the methods of immunocytochemistry
\end{abstract}

Correspondence to: Dr Shi-Quan Liu or Professor Jie-An Huang, Department of Gastroenterology, The First Affiliated Hospital of Guangxi Medical University, 6 Shuangyong Road, Nanning, Guangxi 530021, P.R. China

E-mail: poempower@163.com

E-mail: 1404991727@qq.com

${ }^{*}$ Contributed equally

Abbreviations: KSR1, kinase suppressor of Ras 1; ERK, extracellular signal-regulated kinase; EGb, Ginkgo biloba extract

Key words: gastric cancer, kinase suppressor of Ras 1, extracellular signal-regulated kinase, Ginkgo biloba extract, tumorigenesis, chemoresistance and western blot analysis. EGb 761 not only suppressed expression of these proteins induced by cisplatin (CDDP) and etoposide in SGC-7901 cells, but also inhibited expression of these proteins in the SGC-7901/CDDP cells. Meanwhile, the proliferation-suppressing and apoptosis-inducing capacities of CDDP and etoposide were enhanced following combined treatment with EGb 761. Moreover, EGb 761 reduced the malondialdehyde (MDA) content and elevated the activities of superoxide dismutase (SOD) and glutathione peroxidase (GSH-Px) in the tumor cells. These results confirmed that activation of the KSR1-mediated ERK1/2 signaling pathway may contribute to tumorigenesis, metastasis and chemoresistance of human gastric cancer. EGb 761 enhanced the chemotherapy sensitivity and reversed the chemoresistance through suppression of the KSR1-mediated ERK1/2 pathway in gastric cancer cells, and the underlying mechanism may be related to its antioxidative activity.

\section{Introduction}

Gastric cancer is one of the most prevalent malignancies in Eastern Asia and it is one of the leading causes of cancer-related deaths worldwide (1). To date, chemotherapy is still an important treatment for patients with advanced gastric cancer. However, the efficacy of chemotherapeutic agents is severely limited due to chemoresistance and adverse side effects. Evidence has shown that chemotherapy sensitivity and chemoresistance are tightly correlated with signal transduction pathways and genetic events. Recently, kinase suppressor of Ras 1 (KSR1) and its downstream extracellular signal-regulated kinase (ERK) signaling pathway have received much attention (2).

KSR1 is an essential scaffold protein of the Ras/Raf/MAPK cascade that facilitates the activation of ERK (3). Studies have shown that the expression of KSR1 is upregulated in many types of cancer and is required for cell proliferation, apoptosis and cell-cycle reinitiation (4-6). Moreover, KSR1 was confirmed to contribute to tumorigenesis through the MAPK cascade in a mouse model $(7,8)$. In addition, a screening experiment showed that the expression of KSR1 is correlated with cancer cell sensitivity to anticancer drugs (9). Metastasis suppressor 
nm23-H1 was found to bind directly to KSR1 and modulate the scaffold binding patterns, therefore facilitating its degradation and decreased ERK activation, resulting in elevated tumor cell sensitivity to cancer therapeutics (10). Our previous study also showed that etoposide activated the MAPK/ERK signaling pathway, which reduced the chemotherapy sensitivity of gastric cancer cells via suppressing expression of p53 and enhancing expression of c-Myc (11). These results indicate a significant role of the KSR1-mediated ERK signaling pathway in the pathogenesis of tumors and it might be a potential therapeutic target of chemotherapy resistance. The identification of an effective agent with few adverse side effects to suppress the KSR1-mediated ERK signaling pathway may be a potential method to reverse chemotherapy resistance in gastric cancer.

Ginkgo biloba extract (EGb), a natural antioxidant, is a well-known and inexpensive herb that has been used without side effects for centuries (12). Recently, EGb has attracted considerable attention for its antitumor properties. EGb was able to induce cell apoptosis, suppress cell proliferative, migration and tumor progression of cancer (13-15). Moreover, it was reported that EGb had chemopreventive effects in cancer cells and rat models through antiproliferation, antioxidant, anti-angiogenic and apoptosis-inducing activities $(15,16)$. Further study indicated that the proliferation, migration and tube formation of endothelial cells were inhibited by EGb by inhibiting the Raf-MEK-ERK cascade (17). In gastric cancer, studies also showed that EGb increased antioxidative activity and inhibited the progression of gastric precancerous lesions and gastric cancer via regulation of cell proliferation and apoptosis $(18,19)$. Our previous study also revealed that EGb 761 enhanced CDDP and etoposide-induced apoptosis of gastric cancer cells possibly by suppressing the protein expression of ERK and p-ERK (20). These findings provide a rational basis for tumor prevention and adjuvant therapy using EGb 761, and the KSR1/ERK signaling pathway may play an important role in this process.

In the present study, correlations of KSR1, p-KSR1, ERK and p-ERK expression with clinicopathological parameters were investigated in gastric cancer tissues. Moreover, the effects of EGb 761 on oxidative stress, the KSR1-mediated ERK signaling pathway and the chemotherapy sensitivity of gastric cancer cells and of multidrug resistant gastric cancer cells were investigated. The aims were to investigate the role of the KSR1-mediated ERK signaling pathway in tumor progression and development of chemoresistance, and to explore the potential of EGb 761 in enhancing the chemotherapeutic sensitivity and reversing the chemoresistance of gastric cancer.

\section{Materials and methods}

Tissue specimens. A total of 62 fresh gastric cancer and matched distant normal gastric tissues of patients were collected from the First Affiliated Hospital of Guangxi Medical University, Guangxi, China. All tissues were obtained from surgery; one-half of each tissue was snap-frozen immediately in liquid nitrogen and stored at $-80^{\circ} \mathrm{C}$ and the other half was formalin-fixed and paraffin-embedded. All patients had not received chemotherapy or radiation therapy before tumor resection. This study was approved by the Medical Ethics Committee of The First Affiliated Hospital of Guangxi
Medical University, Guangxi, China. Each patient provided consent in a written informed consent form and the Ethics Committee approved the consent procedure.

Immunohistochemical staining. Paraffin-embedded tissue blocks were serially sectioned at $4 \mu \mathrm{m}$. After being deparaffinized and rehydrated, the sections were treated with $3.0 \%$ hydrogen peroxide in methanol and performed in a microwave for $15 \mathrm{~min}$. Then, the sections were blocked with normal rabbit serum followed by incubation overnight at $4^{\circ} \mathrm{C}$ with rabbit anti-human monoclonal ERK (1:100) and p-ERK (1:100) primary antibodies (both from Cell Signaling Technology, Inc., Beverly, MA, USA) or rabbit anti-human polyclonal KSR1 (1:200) and p-KSR1 (1:200) primary antibodies (both from Beijing Biosynthesis Biotechnology Co., Ltd., Beijing, China). The sections were washed with PBS and incubated with the secondary antibody at room temperature for $30 \mathrm{~min}$, and sections were stained using a streptavidin-peroxidase detection system. Antibody binding was visualized using diaminobenzidine as chromogen and counterstained with hematoxylin. The sections incubated with PBS instead of the primary antibody served as a negative control.

The positive staining of cancer cells was estimated based on the extent and intensity. i) The extent of positive cells was scored as: 0 , positive-staining cells $\leq 5 \%$; 1 , positive-staining cells $6-25 \%$; 2 , positive-staining cells 26-50\%; and 3, positive-staining cells $>50 \%$. ii) The intensity of staining was scored as: 0 , achromatic; 1 , light yellow; 2 , yellow; and 3 , brown. The scores from $\mathrm{i}$ and ii were multiplied to produce a weighted score for each case, and the staining grade was defined as negative $(-$, score $\leq 1)$, positive $(+$, score, $\geq 2$ and $<4$ ) or strong positive $(++$, score $\geq 4)$.

Real-time fluorescent quantitative PCR. Total RNA was extracted from the gastric cancer and matched normal tissues using TRIzol reagent (Invitrogen Co., Carlsbad, CA, USA). First-strand cDNA was synthesized from $1 \mu \mathrm{g}$ of total-RNA using PrimeScript ${ }^{\circledR}$ First Strand cDNA Synthesis kit (Takara Biotechnology Co., Ltd., Dalian, Liaolin, China) according to the manufacturer's instructions. Real-time PCR was performed on the Applied Biosystems StepOne Real-Time PCR system (Applied Biosystems) using the comparative $\mathrm{Ct}$ quantitation method. The first-strand cDNA was subjected to PCR amplification with 40 cycles consisting of $95^{\circ} \mathrm{C}$ for $2 \mathrm{~min}, 60^{\circ} \mathrm{C}$ for $30 \mathrm{sec}$, and $72^{\circ} \mathrm{C}$ for $5 \mathrm{~min}$ using the following primers: KSR1, 5'-AGG GCA TCG TAC ACA AAG ATC TCA-3' (sense) and 5'-GGG ACA GCT TTA GCT GGT TCT CAC-3' (antisense); ERK1, 5'-CGT TGG TAC AGG GCT CCA GAA-3' (sense) and 5'-CTG CCA GAA TGC AGC CTA CAGA-3' (antisense); ERK2, 5'-TCA TCG GCA TCC GAG ACA-3' (sense) and 5'-TCT CCA TCA GGT CCT GCA CAA-3' (antisense); GAPDH, 5'-AAG GTG AAG GTC GGA GTC AAC-3' (sense) and 5'-GGG GTCA TTG ATG GCA ACA ATA-3' (antisense). $\mathrm{Ct}$ values for duplicate samples were averaged and the amounts of mRNA relative to hprt were calculated using the $\Delta \Delta \mathrm{Ct}$ method. All qRT-PCR reactions yielded products with single peak dissociation curves.

Cell culture and survival analysis. Human gastric cancer SGC-7901 and multidrug resistant SGC-7901/CDDP cell lines 
were obtained from the Shanghai Institute of Cell Biology, Chinese Academy of Sciences Cell Bank. Cells were cultivated in high glucose Dulbecco's modified Eagle's medium (DMEM; Hyclone Co., Logan, UT, USA) supplemented with 10\% FBS in an atmosphere of $5 \% \mathrm{CO}_{2}$ at $37^{\circ} \mathrm{C}$. Cell viability was determined using a colorimetric MTT assay (Sigma-Aldrich Co., St. Louis, MO, USA). In brief, the cells seeded in a 96-well plate from the different groups were treated with CDDP, etoposide and/or EGb 761. Cells treated with an equal amount of $0.9 \% \mathrm{NaCl}$ instead of the drugs served as the control group. Then $20 \mu \mathrm{l}$ solution of MTT was added to each well and incubated at $37^{\circ} \mathrm{C}$ for $4 \mathrm{~h}$. The solution was carefully removed, and dimethyl sulfoxide (DMSO) (Invitrogen) was added to each well to solubilize MTT. The absorbance (A) was measured at $490 \mathrm{~nm}$, and the cell viability was expressed as A value of the experimental cells/control cells x $100 \%$.

Flow cytometric analysis. Cells were washed twice with PBS and resuspended in binding buffer at a density of $1 \times 10^{6}$ cells $/ \mathrm{ml}$, and cell apoptosis was detected using Annexin V-FITC/propidium iodine (PI) kits (Roche Co. Ltd., Basel, Switzerland). In brief, Annexin V-FITC was added to the sample and incubated for $20 \mathrm{~min}$ at room temperature in the dark, and then $5 \mu \mathrm{l} \mathrm{PI}$ buffer was added and incubated for $5 \mathrm{~min}$ at $4^{\circ} \mathrm{C}$ in the dark. Finally, the samples were evaluated by flow cytometry, and data were analyzed using CellQuest software.

Western blot analysis. Tissue or cell samples were lysed in lysis buffer, and the lysate was incubated on ice for $20 \mathrm{~min}$ and centrifuged at $15,184 \mathrm{x}$ g for $10 \mathrm{~min}$ at $4^{\circ} \mathrm{C}$. The supernatant was collected for protein detection, and the concentration of total protein was evaluated by the BCA method. Then, $20 \mu \mathrm{g}$ protein of each sample was separated on SDS-PAGE and electroblotted onto a nitrocellulose membrane followed by blocking with $5 \%$ non-fat milk in TBST. The membrane was then incubated with rabbit anti-human monoclonal $\beta$-actin $(1: 8,000)$ (Cell Signaling Technology), ERK (1:500) and p-ERK (1:500) primary antibodies or rabbit anti-human polyclonal KSR1 (1:200) and p-KSR1 (1:200) primary antibodies, and subsequently incubated with a peroxidase-conjugated secondary antibody. Finally, the protein signals were visualized using Pierce enhanced chemiluminescence reaction Western Blotting Substrate (Pierce Co., Rockford, IL, USA) and exposed to medical X-ray film. The blotting bands were scanned and quantitated by a densitometer. The relative expression level was expressed as the relative absorbance (A) value of the target protein $/ \beta$-actin.

Immunocytochemistry. Cells were plated onto slides fixed in a culture dish at a density of $2 \times 10^{4}$ cells $/ \mathrm{ml}$, followed by treatment with $\mathrm{EGb} 761$ or $0.9 \% \mathrm{NaCl}$ for $24 \mathrm{~h}$. The slides were fixed with ice-cold $100 \%$ methanol, quenched with $0.3 \% \mathrm{H}_{2} \mathrm{O}_{2}$ and blocked with normal goat serum. After incubation for $30 \mathrm{~min}$ with the primary antibodies (the same as the western blot analysis) and washing, the biotinylated secondary antibodies were added for $30 \mathrm{~min}$, washed, and followed by preformed avidin/DH-biotinylated horseradish peroxidase $\mathrm{H}$ complex for $30 \mathrm{~min}$. Slides were then overlaid with DAB, rinsed, dried, mounted and coverslipped. Image Pro Plus analysis system was used to analyze the protein expression. Five visual fields
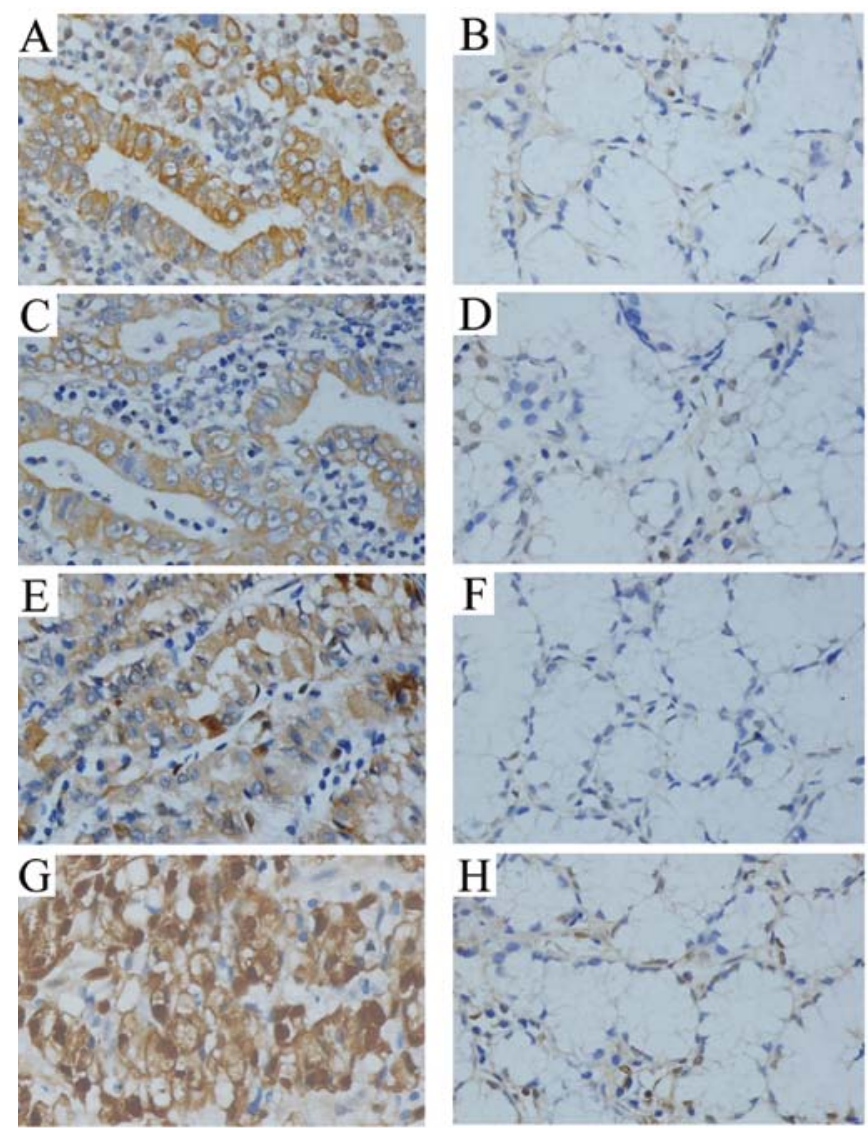

Figure 1. Expression of KSR1, p-KSR1, ERK1/2 and p-ERK1/2 in the gastric cancer and normal tissues. Immunohistochemical staining detection was performed in paraffin-embedded specimens from gastric cancer and matched normal tissues using a microscope (magnification, $\mathrm{x} 400$ ). (A) The expression of KSR1 in gastric cancer. (B) The expression of KSR1 in normal gastric mucosa. (C) The expression of p-KSR1 in gastric cancer. (D) The expression of p-KSR1 in normal gastric mucosa. (E) The expression of ERK1/2 in gastric cancer. (F) The expression of ERK1/2 in normal gastric mucosa. (G) The expression of p-ERK1/2 in gastric cancer. $(\mathrm{H})$ The expression of p-ERK1/2 in normal gastric mucosa. KSR1, kinase suppressor of Ras 1; ERK, extracellular signal-regulated kinase.

of each slide were selected randomly, and the total area and accumulated optical density were detected. The expression level was expressed as average optical density (AOD): $\mathrm{AOD}=$ accumulated optical density/total area.

Analysis of oxidative stress levels in the gastric cancer cells. Cells were homogenized in PBS and centrifuged at $1,687 \mathrm{x}$ g for $10 \mathrm{~min}$ at $4^{\circ} \mathrm{C}$. As previously described in detail (21), the supernatant was obtained for detection of malondialdehyde (MDA) content and the activities of superoxide dismutase (SOD) and glutathione peroxidase (GSH-Px). SOD activity was measured by the inhibition of nitroblue tetrazolium (NBT) reduction by the $\mathrm{O}_{2}$-generated by xanthine/xanthine oxidase system. One SOD activity unit was defined as the enzyme causing $50 \%$ inhibition in a 1-ml reaction solution/mg protein and the result was expressed as U/mg protein. GSH-Px activity was tested by measuring the reduction in glutathione $(\mathrm{GSH}) / \mathrm{min}$ on the base of its catalysis. GSH reacts with 5'-dithiobis-p-nitrobenzoic acid (DTNB), and produces yellow-colored compounds, which are detected at $412 \mathrm{~nm}$ and represent a reduction in GSH. One unit of enzyme activity is defined as a decrease in 
Table I. Expression of KSR1, p-KSR1, EKR1/2 and p-ERK1/2 in gastric cancer and matched normal tissues.

\begin{tabular}{|c|c|c|c|c|c|c|c|c|c|}
\hline \multirow[b]{2}{*}{ Samples } & \multirow[b]{2}{*}{$\mathrm{N}$} & \multicolumn{2}{|l|}{ KSR1 } & \multicolumn{2}{|c|}{ p-KSR1 } & \multicolumn{2}{|l|}{ ERK1/2 } & \multicolumn{2}{|c|}{$\mathrm{p}$-ERK $1 / 2$} \\
\hline & & Positive, n (\%) & P-value & Positive, n (\%) & $\mathrm{P}$-value & Positive, n (\%) & P-value & Positive, n (\%) & P-value \\
\hline Cancer tissues & 62 & $40(64.52)$ & 0.000 & $43(69.38)$ & 0.000 & $45(72.58)$ & 0.000 & $42(67.74)$ & 0.000 \\
\hline Normal tissues & 62 & $14(22.58)$ & & $14(22.58)$ & & $17(27.42)$ & & $15(24.19)$ & \\
\hline
\end{tabular}

Positive expression consists of + and ++. KSR1, kinase suppressor of Ras 1; ERK, extracellular signal-regulated kinase.

Table II. Correlation between the expression of KSR1, p-KSR1, ERK1/2 and p-ERK1/2 in gastric cancer tissues.

\begin{tabular}{|c|c|c|c|c|c|c|c|c|c|c|}
\hline \multirow[b]{2}{*}{ Expression } & \multicolumn{5}{|c|}{ ERK1/2 expression } & \multicolumn{5}{|c|}{ p-ERK $1 / 2$ expression } \\
\hline & - & + & ++ & Correlation & P-value & - & + & ++ & Correlation & P-value \\
\hline \multicolumn{11}{|l|}{ KSR1 } \\
\hline- & 10 & 8 & 4 & 0.435 & 0.000 & 11 & 8 & 3 & 0.414 & 0.001 \\
\hline+ & 5 & 5 & 7 & & & 6 & 5 & 6 & & \\
\hline++ & 2 & 6 & 15 & & & 3 & 7 & 13 & & \\
\hline \multicolumn{11}{|l|}{ p-KSR1 } \\
\hline- & 9 & 7 & 3 & 0.426 & 0.001 & 10 & 7 & 2 & 0.417 & 0.001 \\
\hline+ & 5 & 6 & 7 & & & 6 & 6 & 6 & & \\
\hline++ & 3 & 6 & 16 & & & 4 & 7 & 14 & & \\
\hline
\end{tabular}

KSR1, kinase suppressor of Ras 1; ERK, extracellular signal-regulated kinase.

$1 \mu \mathrm{M} \mathrm{GSH} / \mathrm{min}$ for $1 \mathrm{mg}$ protein after the decrease in GSH of the non-enzymatic reaction is subtracted and the result is expressed as U/mg protein. MDA was assayed by the measurement of thiobarbituric acid reactive substance (TBARS) levels at $532 \mathrm{~nm}$. The results are expressed as nmol/mg protein. All above measurements were performed according to the protocol specified in each kit.

Statistical analysis. Data are presented as mean \pm standard deviation (SD). The significance of the difference between the groups was assessed by the Student's two-tailed t-test. The significance between proteins and clinicopathological characteristics of the patients was assessed with the $\chi^{2}$ test. The correlation between KSR1 (p-KSR1) and ERK (p-ERK) was calculated by the method of Pearson's correlation coefficient. Differences were considered significant at $\mathrm{P}<0.05$.

\section{Results}

Immunohistochemical analysis of KSR1, p-KSR1, ERK1/2 and $p-E R K 1 / 2$ in the gastric cancer and normal tissues. Immunohistochemical staining showed that the expression of KSR1, p-KSR1, ERK1/2 and p-ERK1/2 was present in the cytoplasm and staining of KSR1, p-KSR1, ERK1/2 and p-ERK $1 / 2$ in the cancer tissues was significantly stronger than that in the matched normal tissue (Fig. 1). The positive staining rates of cancerous tissues were significantly higher than those of the normal tissues (Table I). Moreover, there was a close correlation between the expression of KSR1 (p-KSR1)

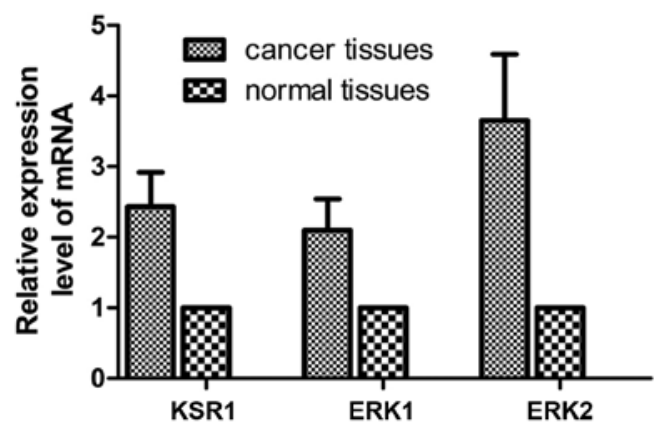

Figure 2. mRNA expression of KSR1, ERK1 and ERK2 in the cancer and matched normal tissues. Real-time fluorescent quantitative PCR was used to detect the mRNA expression. The reaction products of PCR were initially confirmed by agarose gel electrophoresis and the fluorescent-temperature change curve indicated that the products were pure.

and ERK1/2 (p-ERK1/2) (Table II). Coexpression of KSR1, p-KSR1, ERK1/2 and p-ERK1/2 was significantly associated with histological grade, TNM stage, lymph node and distant metastasis, but there was no correlation between the expression levels and age or gender (Table III).

Real-time fluorescent quantitative PCR detection of KSRl, ERK1 and ERK2 in the gastric cancer and normal tissues. The mRNA expression level was detected in 62 paired gastric cancer and matched normal tissues. Compared with the normal tissues, the relative mRNA copy values of KSR1, ERK1 and 
Table III. Clinicopathological characteristics and their association with the protein expression in the gastric cancer tissues.

\begin{tabular}{|c|c|c|c|c|c|c|c|c|c|c|c|c|c|}
\hline \multirow{2}{*}{$\begin{array}{l}\text { Clinicopathological } \\
\text { characteristics }\end{array}$} & \multirow[b]{2}{*}{$\mathrm{N}$} & \multicolumn{2}{|c|}{ KSR1 } & \multirow[b]{2}{*}{ P-value } & \multicolumn{2}{|c|}{ p-KSR1 } & \multirow[b]{2}{*}{ P-value } & \multicolumn{2}{|c|}{ ERK1/2 } & \multirow[b]{2}{*}{ P-value } & \multicolumn{2}{|c|}{ p-ERK1/2 } & \multirow[b]{2}{*}{ P-value } \\
\hline & & + & - & & + & - & & + & - & & + & - & \\
\hline \multicolumn{14}{|l|}{ Gender } \\
\hline Male & 37 & 25 & 12 & 0.541 & 27 & 10 & 0.452 & 30 & 7 & 0.068 & 28 & 9 & 0.104 \\
\hline Female & 25 & 15 & 10 & & 16 & 9 & & 15 & 10 & & 14 & 11 & \\
\hline \multicolumn{14}{|l|}{ Age (years) } \\
\hline$\leq 50$ & 22 & 13 & 9 & 0.508 & 16 & 6 & 0.669 & 17 & 5 & 0.539 & 16 & 6 & 0.533 \\
\hline$>50$ & 40 & 27 & 13 & & 27 & 13 & & 28 & 12 & & 26 & 14 & \\
\hline \multicolumn{14}{|l|}{ Histological grade } \\
\hline $\begin{array}{l}\text { Well and moderately } \\
\text { differentiated }\end{array}$ & 29 & 11 & 18 & 0.000 & 13 & 16 & 0.000 & 14 & 15 & 0.000 & 16 & 13 & 0.047 \\
\hline Poorly differentiated & 33 & 29 & 4 & & 30 & 3 & & 31 & 2 & & 26 & 7 & \\
\hline \multicolumn{14}{|l|}{ TNM stage } \\
\hline $\mathrm{I}+\mathrm{II}$ & 23 & 9 & 14 & 0.001 & 10 & 13 & 0.001 & 11 & 12 & 0.001 & 12 & 11 & 0.044 \\
\hline III+IV & 39 & 31 & 8 & & 33 & 6 & & 34 & 5 & & 30 & 9 & \\
\hline \multicolumn{14}{|l|}{ Lymph node metastasis } \\
\hline Positive & 42 & 22 & 20 & 0.004 & 25 & 17 & 0.032 & 26 & 16 & 0.006 & 24 & 18 & 0.010 \\
\hline Negative & 20 & 18 & 2 & & 18 & 2 & & 19 & 1 & & 18 & 2 & \\
\hline \multicolumn{14}{|l|}{ Distant metastasis } \\
\hline Positive & 44 & 27 & 17 & 0.048 & 27 & 17 & 0.033 & 28 & 16 & 0.031 & 26 & 18 & 0.023 \\
\hline Negative & 18 & 15 & 3 & & 16 & 2 & & 17 & 1 & & 16 & 2 & \\
\hline
\end{tabular}

KSR1, kinase suppressor of Ras 1; ERK, extracellular signal-regulated kinase.

A

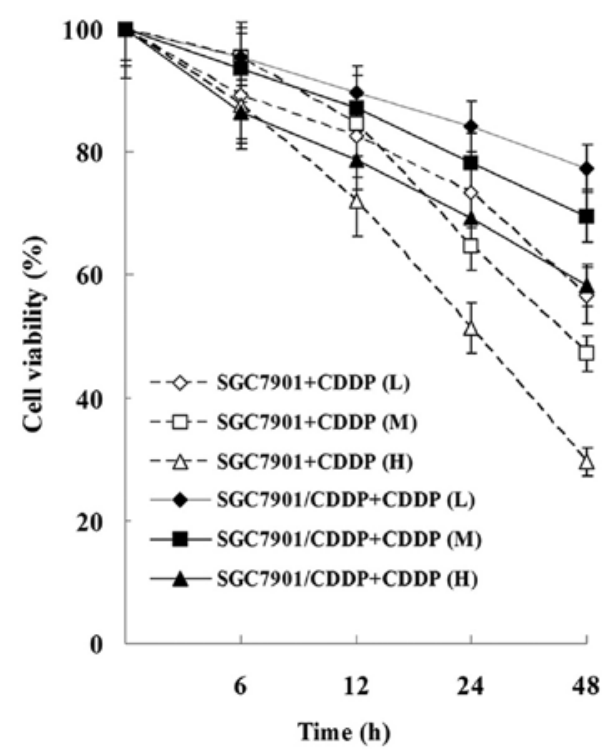

B

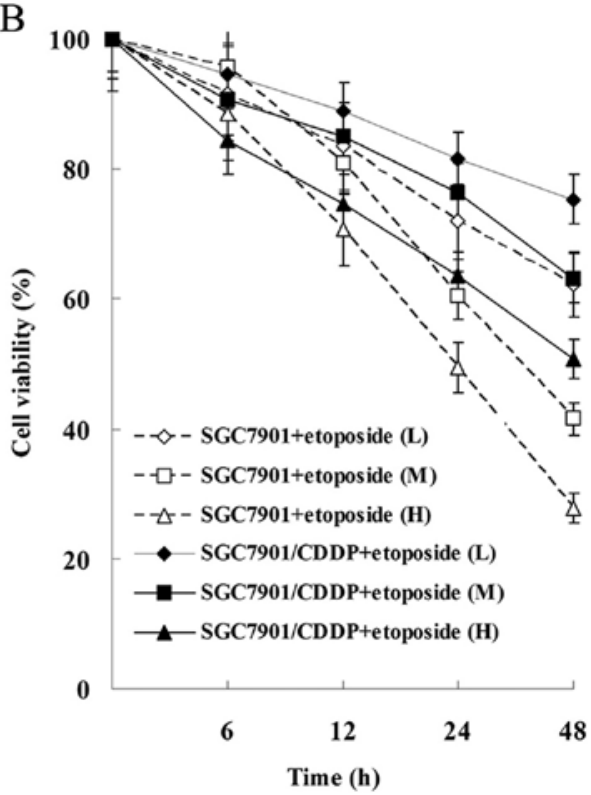

Figure 3. Effects of CDDP and etoposide on tumor cell proliferation. (A) Effect of CDDP on the cell viability of SGC-7901 and SGC-7901/CDDP cells. (B) Effect of etoposide on the cell viability of SGC-7901 and SGC-7901/CDDP cells. Cells were treated with $1 \mu \mathrm{g} / \mathrm{ml}$ (L, low dose), $2 \mu \mathrm{g} / \mathrm{ml}$ (M, medium dose), $4 \mu \mathrm{g} / \mathrm{ml}(\mathrm{H}$, high dose) CDDP or $5 \mu \mathrm{g} / \mathrm{ml}(\mathrm{L}), 10 \mu \mathrm{g} / \mathrm{ml}(\mathrm{M}), 20 \mu \mathrm{g} / \mathrm{ml}(\mathrm{H})$ etoposide for 0, 6, 12, 24 and $48 \mathrm{~h}$. All results shown are the mean \pm SD of 3 independent experiments. CDDP, cisplatin.

ERK2 were $2.43 \pm 0.49,2.10 \pm 0.44$ and $3.65 \pm 0.94$ in the cancer tissues (Fig. 2).
Effects of CDDP and etoposide on the proliferation and apoptosis of SGC-7901 and SGC-7901/CDDP cells. As showed in 

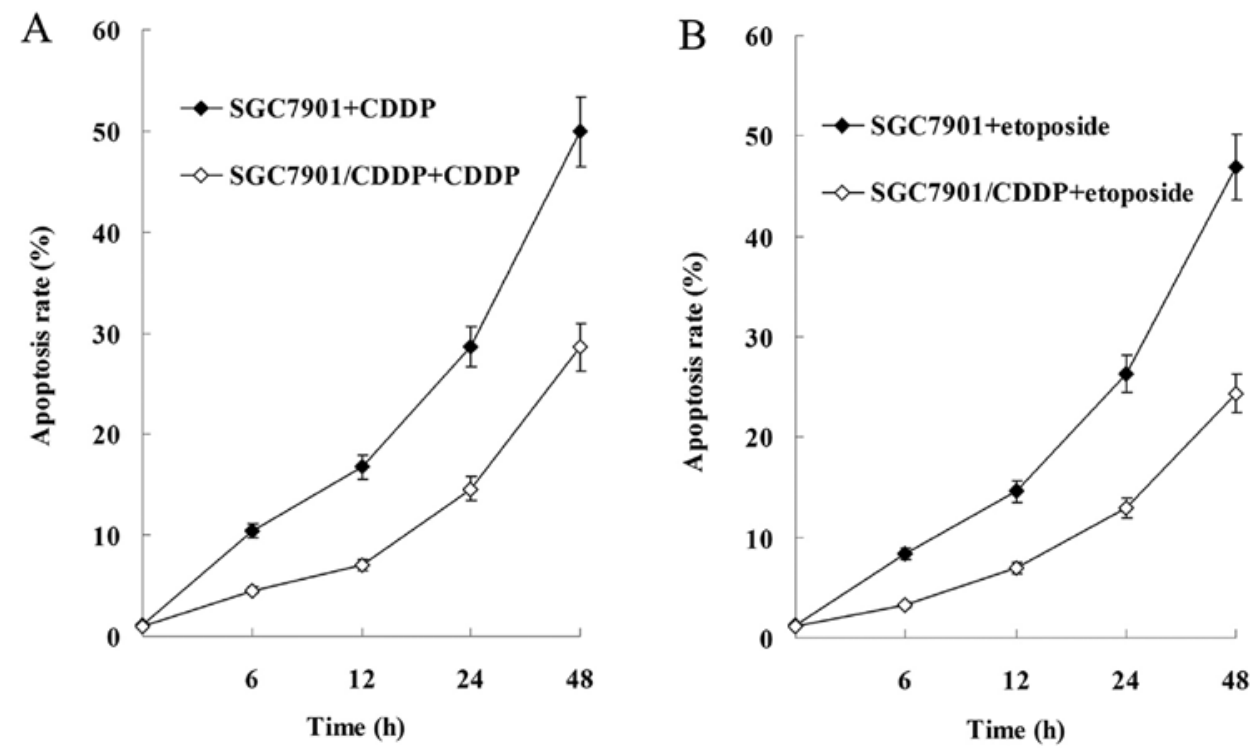

Figure 4. Effects of CDDP and etoposide on tumor cell apoptosis. Cells were treated with $2 \mu \mathrm{g} / \mathrm{ml} \mathrm{CDDP}$ or $10 \mu \mathrm{g} / \mathrm{ml}$ etoposide for $0,6,12,24 \mathrm{and} 48 \mathrm{~h}$. (A) Effect of CDDP on the cell apoptosis in SGC-7901 and SGC-7901/CDDP cells. (B) Effect of etoposide on the cell apoptosis in SGC-7901 and SGC-7901/ CDDP cells. All results shown are the mean \pm SD of 3 independent experiments. CDDP, cisplatin.

A

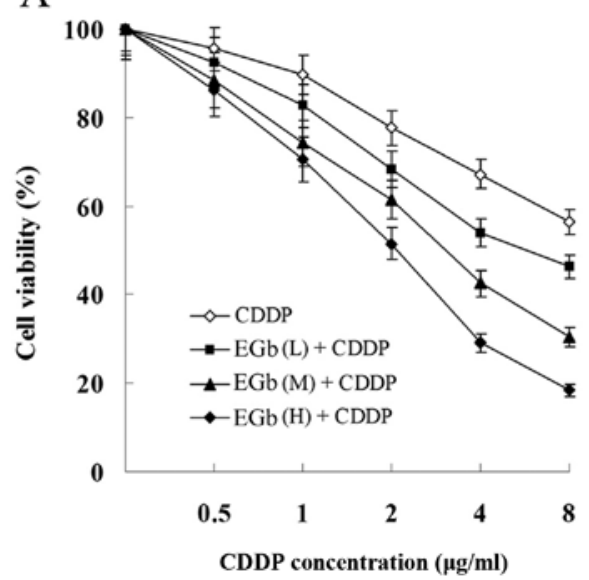

$\mathrm{C}$

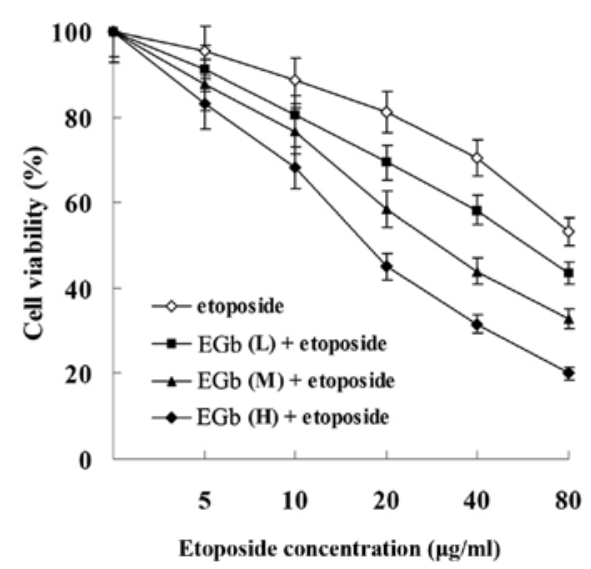

B

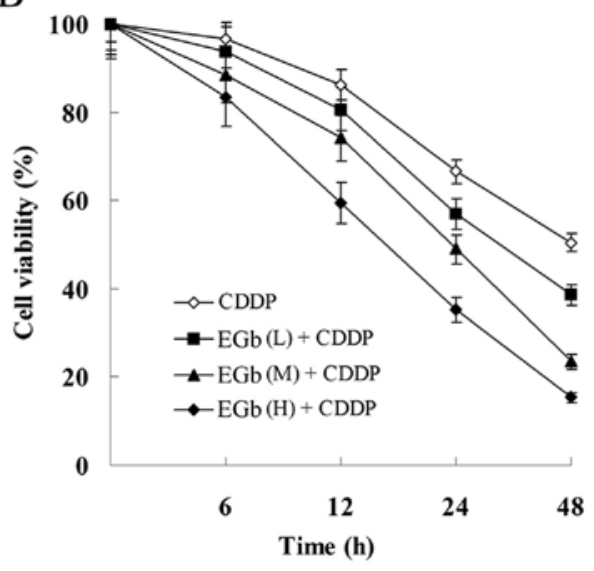

$\mathrm{D}$

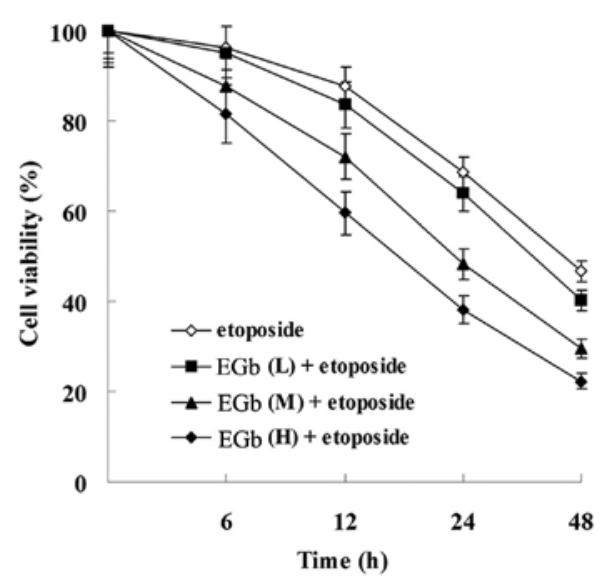

Figure 5. EGb 761 enhances the anti-proliferation effect of CDDP and etoposide in the SGC-7901 cells. (A) Effect of EGb 761 on the proliferation inhibition effect induced by various concentrations of CDDP. Cells were treated with $80 \mu \mathrm{g} / \mathrm{ml}(\mathrm{L}), 320 \mu \mathrm{g} / \mathrm{ml}(\mathrm{M})$ and $1,280 \mu \mathrm{g} / \mathrm{ml}(\mathrm{H})$ EGb 761 and CDDP for $24 \mathrm{~h}$. (B) Effect of EGb 761 on the proliferation inhibition effect induced by $2 \mu \mathrm{g} / \mathrm{ml}$ CDDP for various time. (C) Effect of EGb 761 on the proliferation inhibition effect induced by various concentrations of etoposide. Cells were treated with EGb 761 and various concentrations of etoposide for $24 \mathrm{~h}$. (D) Effect of EGb 761 on the proliferation inhibition effect induced by $10 \mu \mathrm{g} / \mathrm{ml}$ etoposide for various times. All results shown are the mean \pm SD of 3 independent experiments. EGb, Ginkgo biloba extract; CDDP, cisplatin. 


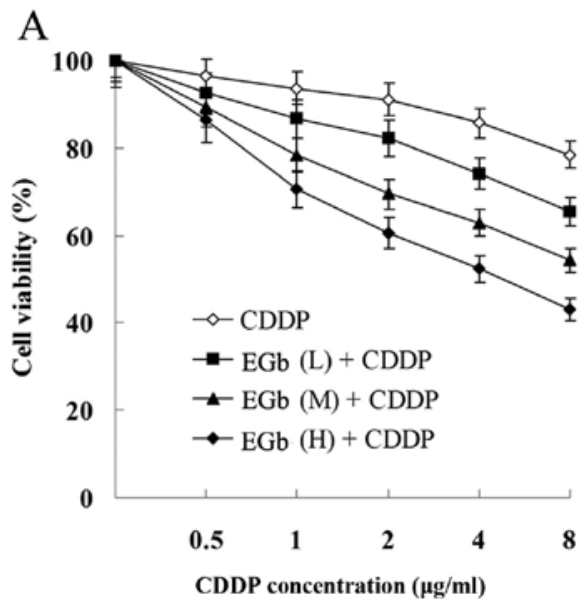

C

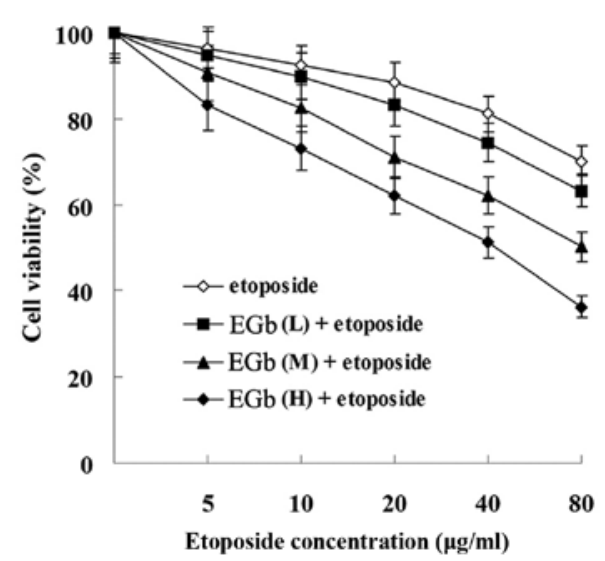

B

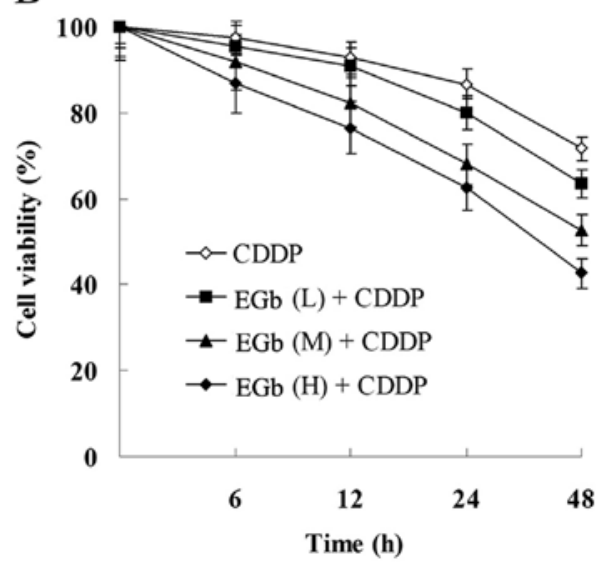

$\mathrm{D}$

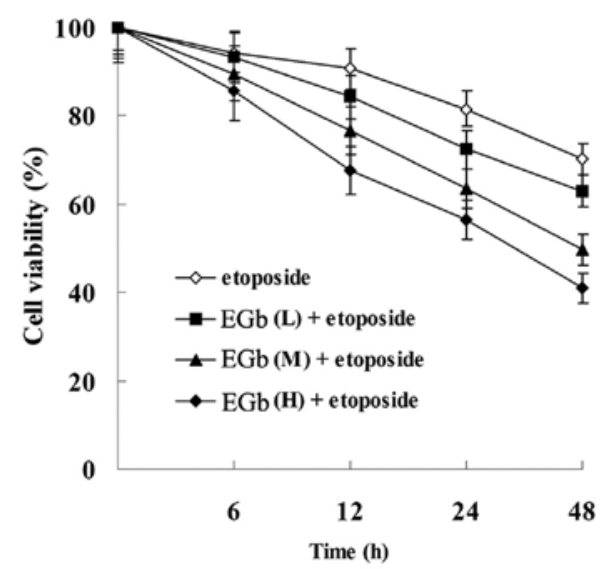

Figure 6. EGb 761 enhances the anti-proliferation effect of CDDP and etoposide in the SGC-7901/CDDP cells. (A) Effect of EGb 761 on the proliferation inhibition effect induced by various concentrations of CDDP. Cells were treated with $80 \mu \mathrm{g} / \mathrm{ml}(\mathrm{L}), 320 \mu \mathrm{g} / \mathrm{ml}(\mathrm{M})$ and $1,280 \mu \mathrm{g} / \mathrm{ml}(\mathrm{H})$ EGb 761 and CDDP for $24 \mathrm{~h}$. (B) Effect of EGb 761 on the proliferation inhibition effect induced by CDDP $(2 \mu \mathrm{g} / \mathrm{ml})$ for various times. (C) Effect of EGb 761 on the proliferation inhibition effect induced by various concentrations of etoposide. Cells were treated with EGb 761 and various concentration of etoposide for $24 \mathrm{~h}$. (D) Effect of EGb 761 on the proliferation inhibition effect induced by etoposide $(10 \mu \mathrm{g} / \mathrm{ml})$ for various times. All results shown are the mean \pm SD of 3 independent experiments. EGb, Ginkgo biloba extract; CDDP, cisplatin.

Fig. 3, the proliferation of SGC-7901 and SGC-7901/CDDP cells was suppressed by CDDP and etoposide in a time- and dose-dependent manner. Moreover, the proliferation suppression level of SGC-7901 cells was more significant than that of SGC-7901/CDDP cells.

Results of the flow cytometric analysis showed that cell apoptosis was induced by CDDP and etoposide in a time-dependent manner, and the apoptosis rate of SGC-7901 cells was significantly higher than that of the SGC-7901/CDDP cells (Fig. 4).

EGb 761 enhances the antiproliferation and apoptosis-inducing effect of CDDP and etoposide in cancer cells. Compared with the groups treated with CDDP and etoposide, combined treatment with EGb 761 reduced the viability of the SGC-7901 (Fig. 5) and SGC-7901/CDDP cells (Fig. 6) in a time- and dose-dependent manner.

The apoptosis of the SGC-7901 and SGC-7901/CDDP cells was strikingly induced by treatment with EGb 761, CDDP and etoposide. The apoptosis rate of SGC-7901 was higher than that of the SGC-7901/CDDP cells. Compared with the CDDP and etoposide groups, the apoptosis rate was obviously elevated following simultaneous treatment with EGb 761 both in the SGC-7901 and SGC-7901/CDDP cells (Fig. 7).

EGb 761 reduces the oxidative stress level of the SGC-7901 and $S G C-7901 / C D D P$ cells. Compared with the control, CDDP and etoposide groups, the activities of SOD and GSH-Px were notably increased, while the content of MDA was obviously decreased in the EGb 761, EGb 761+CDDP and EGb 761+etoposide groups (Table IV and V).

Expression of KSR1, $p$-KSR1, ERK1/2 and p-ERK1/2 in the $S G C-7901$ and $S G C-7901 / C D D P$ cells. Western blot analysis determined that the expression levels of KSR1, p-KSR1, ERK1/2 and p-ERK1/2 in the SGC-7901/CDDP cells were higher than those levels in the SGC-7901 cells (Fig. 8A). Protein expression was also detected using immunocytochemical analysis. KSR1, p-KSR1, ERK1/2 and p-ERK1/2 expression in the SGC-7901/CDDP cells was much higher than that in the SGC-7901 cells (Fig. 8B). 

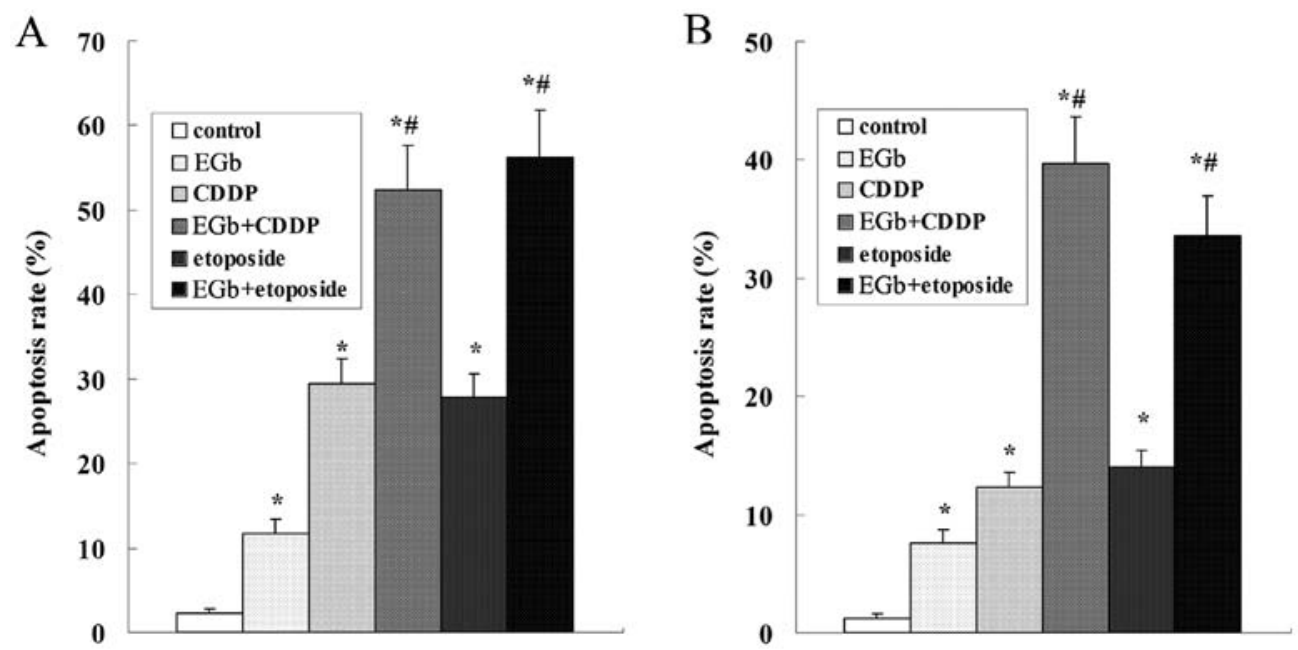

Figure 7. EGb 761 promotes tumor cell apoptosis induced by CDDP and etoposide. Cells were treated with EGb 761 ( $320 \mu \mathrm{g} / \mathrm{ml}), \mathrm{CDDP}(2 \mu \mathrm{g} / \mathrm{ml})$, etoposide $(10 \mu \mathrm{g} / \mathrm{ml})$, EGb 761+CDDP or EGb 761+etoposide for $24 \mathrm{~h}$. Cells treated with an equal amount of $0.9 \% \mathrm{NaCl}$ instead of the drugs served as the control group. (A) Effect of EGb 761 on the apoptosis of SGC-7901 cells. (B) Effect of EGb 761 on the apoptosis of SGC-7901/CDDP cells. All results shown are the mean \pm SD of 3 independent experiments ( $\mathrm{P}<0.01$ vs. control group, ${ }^{\#} \mathrm{P}<0.01$ vs. CDDP or etoposide group). EGb, Ginkgo biloba extract; CDDP, cisplatin.

Table IV. Effects of EGb761 on SOD, GSH-Px and MDA in the SGC-7901 cells.

\begin{tabular}{llll}
\hline Treatment & \multicolumn{1}{c}{$\begin{array}{c}\text { SOD } \\
(\mathrm{U} / \mathrm{mg} \text { prot})\end{array}$} & $\begin{array}{c}\text { GSH-Px } \\
(\mathrm{U} / \mathrm{mg} \text { prot})\end{array}$ & $\begin{array}{c}\text { MDA } \\
(\mathrm{nmol} / \mathrm{mg} \text { prot})\end{array}$ \\
\hline Control & $16.57 \pm 3.20$ & $22.18 \pm 4.36$ & $2.46 \pm 0.38$ \\
EGb & $25.96 \pm 3.57^{\mathrm{a}}$ & $33.59 \pm 5.64^{\mathrm{a}}$ & $1.42 \pm 0.26^{\mathrm{a}}$ \\
CDDP & $17.36 \pm 3.13$ & $23.98 \pm 3.35$ & $2.27 \pm 0.39$ \\
EGb+CDDP & $27.35 \pm 4.84^{\mathrm{a}, \mathrm{c}}$ & $35.78 \pm 6.56^{\mathrm{a}, \mathrm{c}}$ & $1.39 \pm 0.25^{\mathrm{b}, \mathrm{c}}$ \\
Etoposide & $16.23 \pm 2.79$ & $22.87 \pm 4.34$ & $2.33 \pm 0.45$ \\
EGb+etoposide & $26.40 \pm 4.27^{\mathrm{a}, \mathrm{d}}$ & $35.33 \pm 5.90^{\mathrm{a}, \mathrm{d}}$ & $1.40 \pm 0.23^{\mathrm{b}, \mathrm{d}}$
\end{tabular}

${ }^{\mathrm{a}} \mathrm{P}<0.05$ vs. control group, ${ }^{\mathrm{b}} \mathrm{P}<0.01$ vs. control group, ${ }^{\mathrm{c}} \mathrm{P}<0.05$ vs CDDP group, ${ }^{\mathrm{d}} \mathrm{P}<0.05$ vs. etoposide group. EGb, Ginkgo biloba extract; CDDP, cisplatin; MDA, malondialdehyde; SOD, superoxide dismutase; GSH-Px, glutathione peroxidase.

EGb 761 suppresses the expression of KSR1, p-KSR1, ERK1/2 and $p$-ERK1/2 induced by CDDP and etoposide in the $S G C-7901$ cells. As shown in Fig. 9, there was basic expression of KSR1, p-KSR1, ERK1/2 and p-ERK1/2 in the SGC-7901 cells, and the expression of KSR1, p-KSR1, ERK1/2 and p-ERK $1 / 2$ was induced by CDDP and etoposide. Further study indicated that the expression of KSR1, p-KSR1, ERK1/2 and p-ERK1/2 induced by CDDP and etoposide in the SGC-7901 cells was strikingly reduced following combined treatment with EGb 761.

Expression of KSR1, p-KSR1, ERK1/2 and p-ERK1/2 is suppressed by EGb 761 in the SGC-7901/CDDP cells. Western blot analysis determined that the expression of KSR1, p-KSR1, ERK1/2 and p-ERK1/2 in the SGC-7901/CDDP cells was significantly suppressed by EGb 761 (Fig. 10A). Immunocytochemical analysis revealed that the KSR1, p-KSR1, ERK1/2 and p-ERK1/2 expression in the SGC-7901/CDDP
Table V.Effects of EGb 761 on SOD, GSH-Px and MDA in the SGC-7901/CDDP cells.

\begin{tabular}{llll}
\hline Treatment & \multicolumn{1}{c}{$\begin{array}{c}\text { SOD } \\
(\mathrm{U} / \mathrm{mg} \text { prot})\end{array}$} & $\begin{array}{c}\text { GSH-Px } \\
(\mathrm{U} / \mathrm{mg} \text { prot})\end{array}$ & $\begin{array}{c}\text { MDA } \\
(\mathrm{U} / \mathrm{mg} \text { prot})\end{array}$ \\
\hline Control & $15.48 \pm 2.63$ & $20.67 \pm 5.90$ & $2.67 \pm 0.45$ \\
EGb & $23.28 \pm 3.36^{\mathrm{a}}$ & $36.49 \pm 6.62^{\mathrm{a}}$ & $1.53 \pm 0.24^{\mathrm{a}}$ \\
CDDP & $15.86 \pm 3.52$ & $21.42 \pm 4.08$ & $2.92 \pm 0.46$ \\
EGb+CDDP & $24.56 \pm 4.36^{\mathrm{a}, \mathrm{b}}$ & $39.52 \pm 5.09^{\mathrm{a}, \mathrm{c}}$ & $1.68 \pm 0.22^{\mathrm{a}, \mathrm{b}}$ \\
Etoposide & $13.34 \pm 2.53$ & $18.73 \pm 3.64$ & $2.81 \pm 0.37$ \\
EGb+etoposide & $24.12 \pm 4.05^{\mathrm{a}, \mathrm{d}}$ & $36.45 \pm 5.13^{\mathrm{a}, \mathrm{e}}$ & $1.51 \pm 0.31^{\mathrm{a}, \mathrm{e}}$
\end{tabular}

${ }^{\mathrm{a}} \mathrm{P}<0.05$ vs. control group, ${ }^{\mathrm{b}} \mathrm{P}<0.05$ vs. $\mathrm{CDDP}$ group, ${ }^{\mathrm{c}} \mathrm{P}<0.01$ vs CDDP group, ${ }^{d} \mathrm{P}<0.05$ vs. etoposide group, ${ }^{\mathrm{e}} \mathrm{P}<0.01$ vs. etoposide group. EGb, Ginkgo biloba extract; CDDP, cisplatin; MDA, malondialdehyde; SOD, superoxide dismutase; GSH-Px, glutathione peroxidase.

cells was strikingly reduced following combined treatment with EGb 761 (Fig. 10B).

\section{Discussion}

As KSR 1 is an essential scaffold protein of the Ras/Raf/MAPK cascade (3), one of the well-known oncogenic pathways, studies are beginning to explore the biological characteristics of KSR1 in different types of cancer. There are reports that the expression of KSR1 is upregulated in various types of tumors (5). The present research confirmed that KSR1 (dephosphorylated KSR1) and p-KSR1 (phosphorylated KSR1-S392) were overexpressed in gastric cancer tissues. Evidence showed that KSR-1 locates in the cytosol, is phosphorylated on S297 and S392, and is held in an inactive state in quiescent cells. The activation of RAS stimulates the dephosphorylation of KSR-1 on S392 and results in its translocation to the plasma membrane where KSR-1 potentiates the MAPK signaling pathway (8). Thus, the 
A
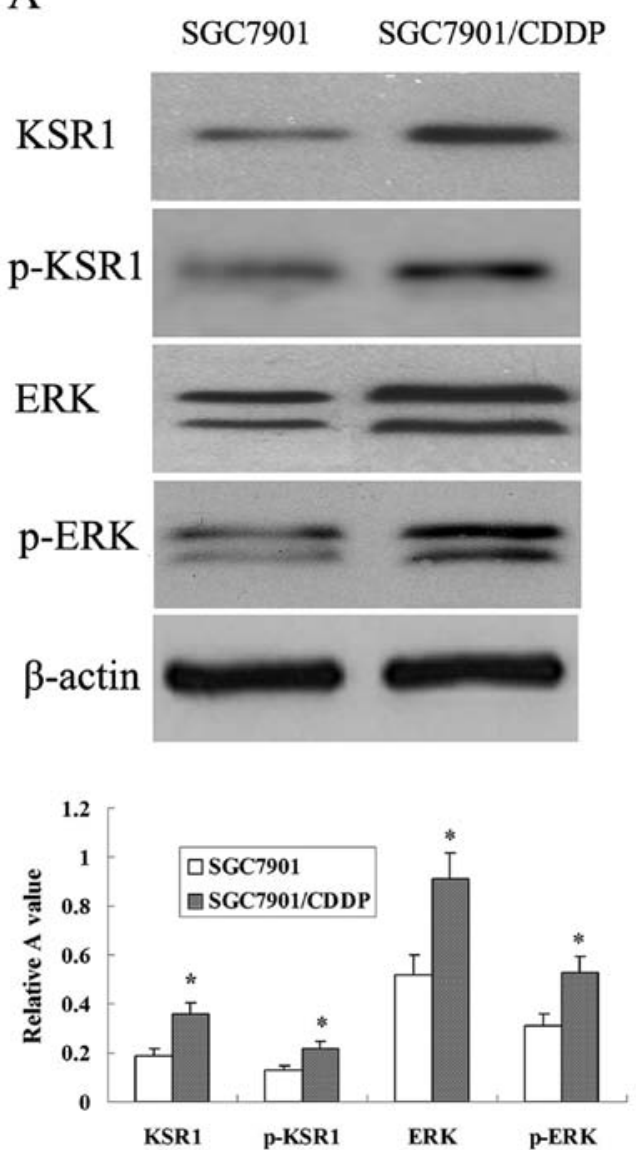

$\mathrm{B}$
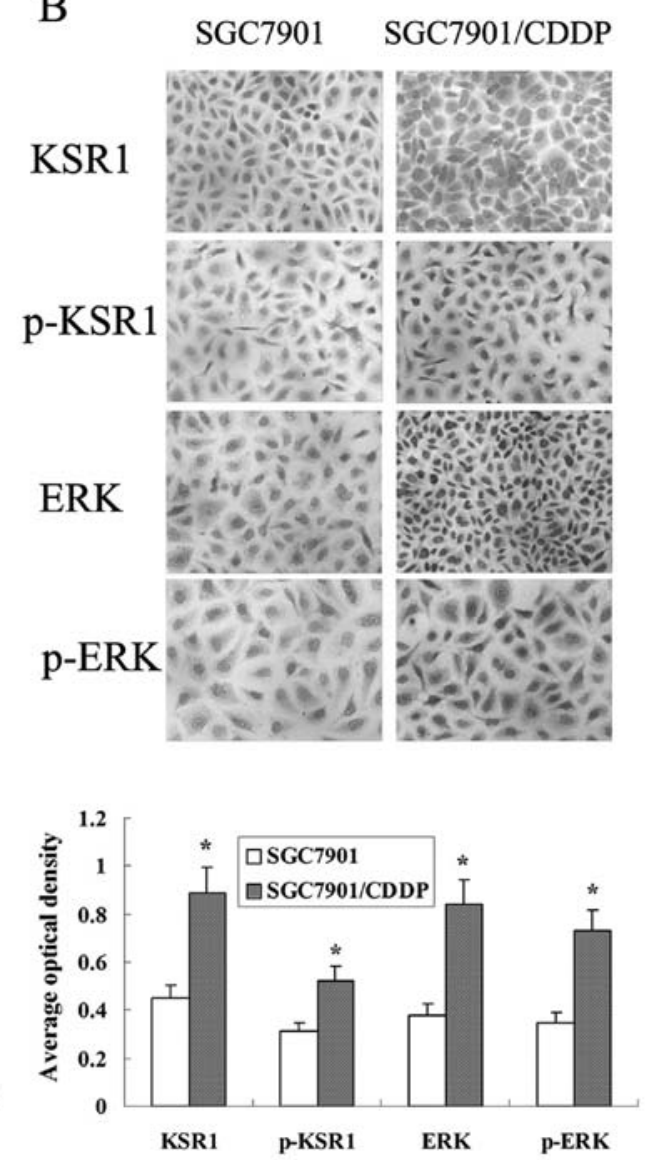

Figure 8. Expression of KSR1, p-KSR1, ERK1/2 and p-ERK1/2 in tumor cells. (A) Western blot analysis of the protein expression. (B) Immunocytochemical detection of the protein expression. The results shown are representative blotting of 3 independent experiments ("P<0.01 vs. SGC-7901 group). KSR1, kinase suppressor of Ras 1; ERK, extracellular signal-regulated kinase.
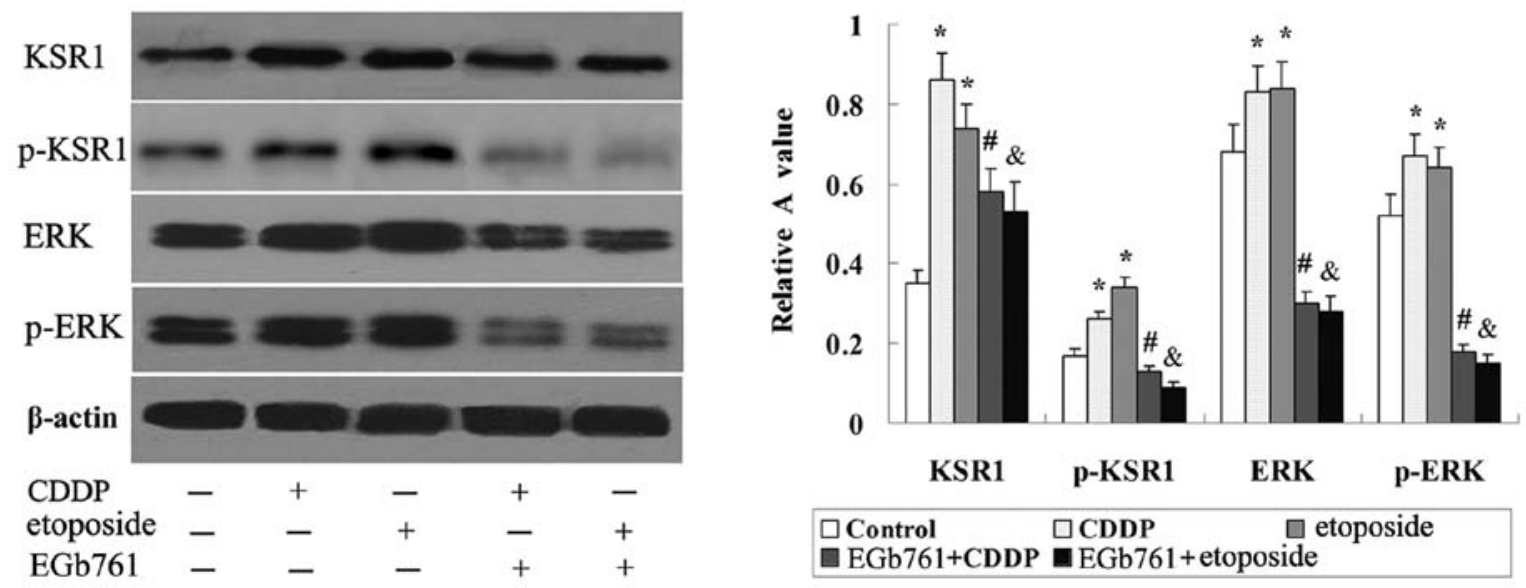

Figure 9. Effects of EGb 761 on the expression of KSR1, p-KSR1, ERK1/2 and p-ERK1/2 in the SGC-7901 cells. SGC-7901 cells were treated with CDDP $(2 \mu \mathrm{g} / \mathrm{ml})$, etoposide $(10 \mu \mathrm{g} / \mathrm{ml}), \mathrm{EGb} 761(320 \mu \mathrm{g} / \mathrm{ml}), \mathrm{CDDP}+\mathrm{EGb} 761$ or etoposide+EGb 761 for $24 \mathrm{~h}$. Cells treated with an equal amount of $0.9 \% \mathrm{NaCl}$ instead of the drugs served as the control group. The results of $\beta$-actin were used to confirm equal loading. The results are representative blotting of 3 independent experiments ( $\mathrm{P}<0.01$ vs. control group, ${ }^{\#} \mathrm{P}<0.01$ vs. CDDP group and ${ }^{\&} \mathrm{P}<0.01$ vs. etoposide group). KSR1, kinase suppressor of Ras 1 ; ERK, extracellular signal-regulated kinase.

expression and activation of KSR1 are both elevated in gastric cancer. Additionally, the overexpression of KSR1 and p-KSR1 was found to correlate with TNM stage, histological grade, lymph node metastasis and distant metastasis, indicating that
KSR1 may contribute to the carcinogenesis and metastasis of gastric cancer.

Evidence also showed that the cell proliferative and oncogenic potential were induced by introduction of KSR1 into 

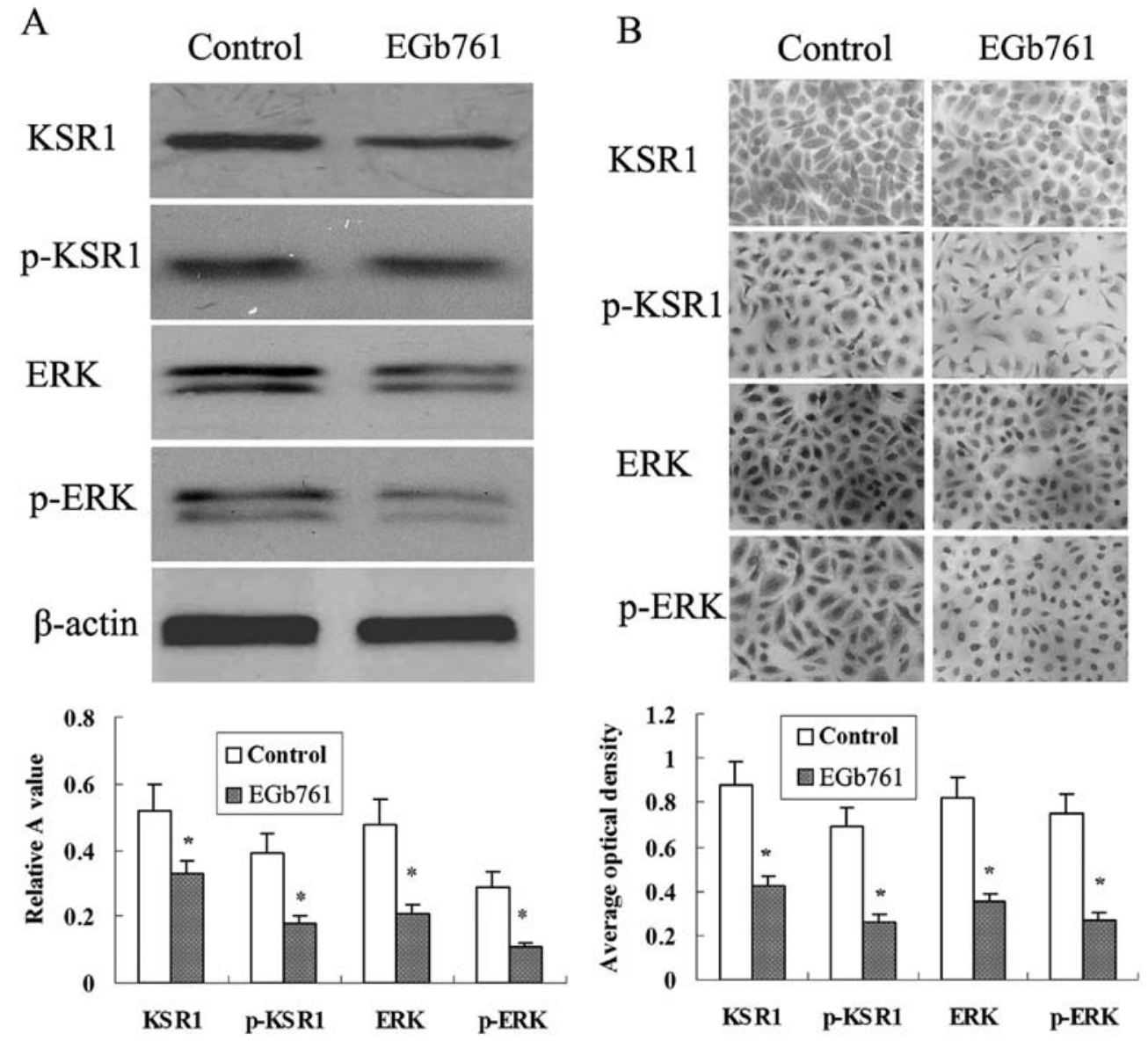

Figure 10. EGb 761 suppresses the expression of KSR1, p-KSR1, ERK1/2 and p-ERK1/2 in SGC-7901/CDDP cells. (A) Western blot analysis of the protein expression. (B) Immunocytochemistry detection of the protein expression. SGC-7901/CDDP cells were treated with EGb 761 (320 $\mu \mathrm{g} / \mathrm{ml})$ for $24 \mathrm{~h}$ and cells treated with an equal amount of $0.9 \% \mathrm{NaCl}$ instead of drugs served as the control group ("P<0.01 vs. control group). EGb, Ginkgo biloba extract; KSR1, kinase suppressor of Ras 1; ERK, extracellular signal-regulated kinase; CDDP, cisplatin.

$\mathrm{KSR}^{-1-}$ mouse embryonic fibroblasts (MEFs). In contrast, the cell transformation was suppressed by the removal of KSR1 (22). Moreover, KSR1 was shown to contribute to the tumorigenesis of B-cell tumors, and skin and pancreatic cancer through the regulation of the MAPK cascade in a mouse model $(7,8,23)$. In gastric cancer, much attention has focused on the ERK signaling pathway, and accumulated data reveal that the MAPK/ERK signaling pathway not only regulates tumor progression but is also involved in the development of chemotherapy resistant $(11,24)$. In gastric cancer tissues, the expression of KSR 1 and p-KSR1 was confirmed to be closely related with the expression of ERK1/2 and p-ERK1/2. Moreover, the expression and activation of KSR1 and ERK1/2 in the multidrug resistance gastric cancer SGC-7901/CDDP cells were higher than these parameters in the SGC-7901 cells. Therefore, the KSR1-mediated ERK1/2 signaling pathway may play an important role in tumorigenesis, metastasis and development of chemoresistance in gastric cancer.

It was reported that continuous infusion of phosphorothioate antisense ODNs targeting KSR1 reduced the tumor growth of human PANC-1 pancreatic and A549 non-small cell lung carcinoma xenografts in nude mice (25), and blocking the activation of the ERK1/2 signaling pathway enhanced the proliferation-suppressing and apoptosis-inducing capacity of chemotherapy reagents in gastric cancer (11). Hence, suppres- sion of the KSR1-mediated ERK1/2 signaling pathway may be a potential therapeutic for enhancing chemotherapy sensitivity and reversing chemoresistance in gastric cancer.

$\mathrm{EGb}$, a natural plant material, has been used as a medicine for centuries with little side effects in China. EGb 761 is a standardized concentrated extract of Ginkgo biloba, containing $24 \%$ flavone glycosides, $6 \%$ terpene lactones and less than 5 ppm ginkgolic acid (26). EGb 761 has been registered as a prescription medicine in many countries. Considerable studies indicate that EGb is beneficial in the prevention and therapy of diseases and degenerative processes associated with oxidative stress (27). In recent years, a number of experimental and clinical evidence has demonstrated that EGb possesses antitumor activities and it has been used to treat several types of solid tumors and malignancies of the blood system $(13,27)$. EGb 761 can inhibit tumor cell proliferation and induce cell apoptosis of colon, pancreatic and oral cavity cancer $(14,28,29)$. However, the anticancer effects of EGb on gastric cancer have not yet been confirmed. One study showed that $\mathrm{EGb}$ can reduce the incidence of mild to severe intestinal metaplasia and dysplasia in rat gastric mucosa induced by oral administration of N-methyl-N'-nitro-N-nitrosoguanidine, and its mechanism may be related to the regulation of cell proliferation and apoptosis (18). In the present study, EGb 761 inhibited cell growth and enhanced the antiproliferation 
and apoptosis-inducing activities of CDDP and etoposide in SGC-7901 and SGC-7901/CDDP cells. These findings suggested that EGb 761 was be able to prevent the development, enhance the chemotherapy sensitivity and reverse the chemoresistance of gastric cancer.

There is evidence that the proliferation, migration and tube formation in vitro and the angiogenesis in vivo of endothelial cells was suppressed by EGb 761 through inhibiting the ERK signaling pathway (17). In the present study, the antiproliferation and apoptosis-inducing activities of CDDP and etoposide were elevated with the suppression of the KSR1-mediated ERK1/2 signaling pathway by EGb 761. These findings indicate that EGb 761 enhanced the chemotherapy sensitivity and reversed the chemoresistance of gastric cancer cells via suppressing the activation of the KSR1-mediated ERK signaling pathway. However, the molecular mechanisms remain to be determined.

It is true that EGb is a potent antioxidant and has been showed to have hydroxyl scavenging property, lipid peroxidation restraining capacity and antioxidant enzyme-like activity $(12,21)$. In gastric cancer cells, the antioxidative activity of EGb 761 was confirmed to be related to the suppression of the KSR1-mediated ERK signaling pathway. Indeed, phosphorylation of ERK1/2 was induced by $\mathrm{H}_{2} \mathrm{O}_{2}$ treatment in lymphocytes and the peak activity was at $\sim 10 \mathrm{~min}$ after ROS exposure (30). Additionally, the growth and proliferation of human cervical cancer cells were enhanced by cancer-derived immunoglobulin $\mathrm{G}$ ( $\mathrm{IgG}$ ) via inducing the production of low level ROS. Inversely, the growth of IgG-deficient cancer cells was inhibited by ROS scavengers through suppressing the MAPK/ERK signaling pathway induced by a low level of intracellular ROS (31). Thus, ROS may play a role in the activation of the ERK1/2 signaling pathway in some cancer cells. EGb 761 may enhance the chemotherapeutic sensitivity and reverse the chemoresistance via suppressing ROS induced by the KSR1-mediated ERK1/2 signaling pathway in gastric cancer. However, there is a report that a high level of glucose contributes to the oxidative stress and activated ERK signaling pathway. Inhibitor of the ERK signaling pathway impaired the production of ROS in pancreatic cancer cells (32), suggesting that the ERK signaling pathway may be involved in the regulation of the production of ROS. The exact mechanism of the KSR1-mediated ERK1/2 signaling pathway and ROS requires further investigation.

In summary, activation of the KSR1-mediated ERK1/2 signaling pathway may contribute to tumorigenesis, metastasis and chemoresistance of gastric cancer. EGb 761 may enhance the chemotherapeutic sensitivity and reverse the chemoresistance through suppressing the activation of the KSR1-mediated ERK1/2 signaling pathway in gastric cancer cells, and the underlying mechanism may be related to its antioxidative activity.

\section{Acknowledgements}

The present study was supported by the National Natural Science Foundation of China (no. 81460380), the Natural Science Foundation of Guangxi (no. 2011GXNSFA018182) and the Project Foundation from the Health Department of Guangxi, China (no. Z2012103).

\section{References}

1. Jemal A, Bray F, Center MM, Ferlay J, Ward E and Forman D: Global cancer statistics. CA Cancer J Clin 61: 69-90, 2011.

2. Shen CH, Yuan P, Perez-Lorenzo R, Zhang Y, Lee SX, Ou Y, Asara JM, Cantley LC and Zheng B: Phosphorylation of BRAF by AMPK impairs BRAF-KSR1 association and cell proliferation. Mol Cell 52: 161-172, 2013.

3. Zhang H, Koo CY, Stebbing J and Giamas G: The dual function of KSR1: a pseudokinase and beyond. Biochem Soc Trans 41: 1078-1082, 2013.

4. Kortum RL, Fernandez MR, Costanzo-Garvey DL, Johnson HJ, Fisher KW, Volle DJ and Lewis RE: Caveolin-1 is required for kinase suppressor of Ras 1 (KSR1)-mediated extracellular signal-regulated kinase $1 / 2$ activation, H-RasV12-induced senescence, and transformation. Mol Cell Biol 34: 3461-3472, 2014.

5. Llobet D, Eritja N, Domingo M, Bergada L, Mirantes C, Santacana M, Pallares J, Macià A, Yeramian A, Encinas M, et al: KSR1 is overexpressed in endometrial carcinoma and regulates proliferation and TRAIL-induced apoptosis by modulating FLIP levels. Am J Pathol 178: 1529-1543, 2011.

6. Razidlo GL, Johnson HJ, Stoeger SM, Cowan KH, Bessho T and Lewis RE: KSR1 is required for cell cycle reinitiation following DNA damage. J Biol Chem 284: 6705-6715, 2009.

7. Lozano J, Xing R, Cai Z, Jensen HL, Trempus C, Mark W, Cannon R and Kolesnick R: Deficiency of kinase suppressor of Ras1 prevents oncogenic ras signaling in mice. Cancer Res 63: 4232-4238, 2003.

8. Cullis J, Meiri D, Sandi MJ, Radulovich N, Kent OA, Medrano M, Mokady D, Normand J, Larose J, Marcotte R, et al: The RhoGEF GEF-H1 is required for oncogenic RAS signaling via KSR-1. Cancer Cell 25: 181-195, 2014.

9. Stoeger SM and Cowan KH: Characterization of kinase suppressor of Ras-1 expression and anticancer drug sensitivity in human cancer cell lines. Cancer Chemother Pharmacol 63: 807-818, 2009.

10. Salerno M, Palmieri D, Bouadis A, Halverson D and Steeg PS: Nm23-H1 metastasis suppressor expression level influences the binding properties, stability, and function of the kinase suppressor of Ras1 (KSR1) Erk scaffold in breast carcinoma cells. Mol Cell Biol 25: 1379-1388, 2005.

11. Liu SQ, Yu JP, Yu HG, Lv P and Chen HL: Activation of Akt and ERK signalling pathways induced by etoposide confer chemoresistance in gastric cancer cells. Dig Liver Dis 38: 310-318, 2006.

12. Ude C, Schubert-Zsilavecz M and Wurglics M: Ginkgo biloba extracts: A review of the pharmacokinetics of the active ingredients. Clin Pharmacokinet 52: 727-749, 2013.

13. Tsai JR, Liu PL, Chen YH, Chou SH, Yang MC, Cheng YJ, Hwang JJ, Yin WH and Chong IW: Ginkgo biloba extract decreases non-small cell lung cancer cell migration by downregulating metastasis-associated factor heat-shock protein 27. PLoS One 9: e91331, 2014.

14. Chen XH, Miao YX, Wang XJ, Yu Z, Geng MY, Han YT and Wang LX: Effects of Ginkgo biloba extract EGb761 on human colon adenocarcinoma cells. Cell Physiol Biochem 27: 227-232, 2011.

15. El Mesallamy HO, Metwally NS, Soliman MS, Ahmed KA and Abdel Moaty MM: The chemopreventive effect of Ginkgo biloba and Silybum marianum extracts on hepatocarcinogenesis in rats. Cancer Cell Int 11: 38, 2011.

16. Park YJ, Kim MJ, Kim HR, Yi MS, Chung KH and Oh SM: Chemopreventive effects of Ginkgo biloba extract in estrogen-negative human breast cancer cells. Arch Pharm Res 36: 102-108, 2013.

17. Koltermann A, Liebl J, Fürst R, Ammer H, Vollmar AM and Zahler S: Ginkgo biloba extract EGb 761 exerts anti-angiogenic effects via activation of tyrosine phosphatases. J Cell Mol Med 13: 2122-2130, 2009.

18. Jiang XY, Qian LP, Zheng XJ, Xia YY, Jiang YB and Sun Y: Interventional effect of Ginkgo biloba extract on the progression of gastric precancerous lesions in rats. J Dig Dis 10: 293-299, 2009.

19. Xu AH, Chen HS, Sun BC, Xiang XR, Chu YF, Zhai F and Jia LC: Therapeutic mechanism of Ginkgo biloba exocarp polysaccharides on gastric cancer. World J Gastroenterol 9: 2424-2427, 2003. 
20. Mao YB, Liu SQ, Tan L, Zhou Q and Huang JA: EGb761 enhances cisplatin and etoposide-induced apoptosis of human gastric cancer SGC-7901 cells. Shijie Huaren Xiaohua Zazhi 21: 3330-3337, 2013 (In Chinese).

21. Liu SQ, Yu JP, Chen HL, Luo HS, Chen SM and Yu HG: Therapeutic effects and molecular mechanisms of Ginkgo biloba extract on liver fibrosis in rats. Am J Chin Med 34: 99-114, 2006.

22. Kortum RL and Lewis RE: The molecular scaffold KSR1 regulates the proliferative and oncogenic potential of cells. Mol Cell Biol 24: 4407-4416, 2004.

23. Gramling MW and Eischen CM: Suppression of Ras/Mapk pathway signaling inhibits Myc-induced lymphomagenesis. Cell Death Differ 19: 1220-1227, 2012.

24. Fukui H, Zhang X, Sun C, Hara K, Kikuchi S, Yamasaki T, Kondo T, Tomita T, Oshima T, Watari J, et al: IL-22 produced by cancer-associated fibroblasts promotes gastric cancer cell invasion via STAT3 and ERK signaling. Br J Cancer 111: 763-771, 2014.

25. Xing HR, Cordon-Cardo C, Deng X, Tong W, Campodonico L, Fuks Z and Kolesnick R: Pharmacologic inactivation of kinase suppressor of ras-1 abrogates Ras-mediated pancreatic cancer. Nat Med 9: 1266-1268, 2003.

26. Smith JV and Luo Y: Studies on molecular mechanisms of Ginkgo biloba extract. Appl Microbiol Biotechnol 64: 465-472, 2004.
27. Mohanta TK, Tamboli Y and Zubaidha PK: Phytochemical and medicinal importance of Ginkgo biloba L. Nat Prod Res 28: 746-752, 2014.

28. Zhang Y, Chen AY, Li M, Chen C and Yao Q: Ginkgo biloba extract kaempferol inhibits cell proliferation and induces apoptosis in pancreatic cancer cells. J Surg Res 148: 17-23, 2008.

29. Kang JW, Kim JH, Song K, Kim SH, Yoon JH and Kim KS: Kaempferol and quercetin, components of Ginkgo biloba extract (EGb 761), induce caspase-3-dependent apoptosis in oral cavity cancer cells. Phytother Res 24 (Suppl 1): S77-S82, 2010.

30. Akhiani AA, Werlenius O, Aurelius J, Movitz C, Martner A, Hellstrand $\mathrm{K}$ and Thorén FB: Role of the ERK pathway for oxidant-induced parthanatos in human lymphocytes. PLoS One 9: e89646, 2014.

31. Wang J, Lin D, Peng H, Huang Y, Huang J and Gu J: Cancer-derived immunoglobulin $\mathrm{G}$ promotes tumor cell growth and proliferation through inducing production of reactive oxygen species. Cell Death Dis 4: e945, 2013.

32. Li W, Wu Z, Ma Q, Liu J, Xu Q, Han L, Duan W, Lv Y, Wang F, Reindl KM, et al: Hyperglycemia regulates TXNIP/TRX/ROS axis via p38 MAPK and ERK pathways in pancreatic cancer. Curr Cancer Drug Targets 14: 348-356, 2014. 